\title{
What is the best predictor for diagnosis of placenta accreta? An evidence-based review
}

\begin{abstract}
Background: Antenatal diagnosis of placenta accreta is important because it could possibly reduce the morbidities. Several attempts including ultrasound, magnetic resonance imaging (MRI), multi-parameter prediction, and cell-free placental mRNA had been studied to establish a good predictor for diagnosis of placenta accreta. We aim to appraise several studies finding at the accuracy value of these predictors.
\end{abstract}

Methods: The search was conducted on the Cochrane Library ${ }^{\circledR}$, PubMed $®$ and EMBASE® with the keywords of "ultrasound", "accreta", and "predict" or "predictor" or "predicting". We used diagnostic appraisal questions developed by Centre of Evidence-Based Medicine (CEBM), University of Oxford.

Result: Appraisal of 8 diagnostic studies involving 1324 patients underwent ultrasound, MRI, cell-free mRNA examination, or their combination for predicting placenta accreta was conducted finding at the diagnostic values. The overall rate of placenta accreta found on these studies were ranging from $8.4 \%$ to $31.8 \%$. Accuracy, sensitivity (Se), specificity $(\mathrm{Sp})$, positive predictive value (PPV), and negative predictive value (NPV) of ultrasound in this study in diagnosing placenta accreta were respectively $64.8 \%-95.3 \%, 17 \%-100 \%$, $78.9 \%-100 \%, 56 \%-100 \%$, and $64,8 \%-100 \%$. The Se, Sp, PPV, and NPV of MRI in predicting placenta accreta derived from 3 studies were respectively $88.89 \%-100 \%, 100 \%$, $100 \%, 92.86 \%-100 \%$. Se, Sp, PPV, and NPV of cell-free placental mRNA for placenta accreta prediction were respectively. $91.7 \%, 78.9 \%, 57.9 \%$ and $96.8 \%$ using the multiple of median (MoM) of 3.325 as the cut-off point.

Conclusion: Ultrasound has a wide range of diagnostic accuracy in predicting placenta accreta. MRI had better diagnostic accuracy for predicting the stage of invasion of placenta. Free-placental mRNA is an objective and promising predictor for diagnosis of placenta accreta.

Keywords: Accuracy, Placenta accrete, Cell-free placental mRNA, MRI, Ultrasound
Volume 5 Issue 5 - 2016

\author{
Adly Nanda Al Fattah, Laurensia Scovani, \\ Rima Irwinda \\ Obstetrics and Gynecology Department, University of \\ Indonesia, Jakarta-Indoensia
}

\begin{abstract}
Correspondence: Adly Nanda Al Fattah, Fetomaternal Division, Obstetrics and Gynecology Department, University of Indonesia, CiptoMangunkusumo Hospital, Jakarta-Indoensia,Tel
\end{abstract} 6281222206663 Email adlynada@yahoo.com

Received: September 08, 2016 | Published: December 05, 2016

\section{Background}

The incidence of placenta accreta and maternal death are substantially increased due to the increased rate cesarean section..$^{1,2}$ The incidence of placenta accreta reported approximately 0.8 to 3 per 1000 deliveries. Maternal mortality related to placenta accreta and its complications occurs approximately as high as $6-7 \% .{ }^{3}$ Placenta accreta is the most common cause for emergency postpartum hysterectomy and may lead to severe maternal morbidity and mortality. ${ }^{4,5}$ It is possibly lead to massive hemorrhage, transfusion, and prolonged length of stay. ${ }^{6}$ Antenatal diagnosis of placenta accreta is important because it could reduce the morbidities, i.e. blood loss and need for blood transfusion..$^{7,8}$ The gold standard diagnosis of placenta accreta will be determined by histology evaluation. ${ }^{9}$ Several attempts i.e. ultrasound index measurement, plasma cell-free placental mRNA assay, ${ }^{10} \mathrm{MRI}$ examination, ${ }^{10}$ clinical risk factors analysis and multi-parameter predictor had been studied to develop better diagnostic accuracy for prediction of placenta accreta. Color-doppler ultrasound remains the first line modality for diagnosis of placenta accreta, however it has a wide-range of predictive values. We aim to appraise several studies finding at the accuracy value of the predictors of placenta accreta.

\section{Clinical question}

Does ultrasound, MRI,

cell-free placental mRNA accurate for diagnosis of placenta accreta?
P (Population): Pregnant women with and without identified risk factors of placenta accreta I (Intervention): Ultrasound, MRI, cell-free placental mRNA C (comparison): Histopathology examination $\mathrm{O}$ (outcome): Placenta accrete

\section{Methods}

\section{Search strategy}

The search was conducted on August 15th 2016 on the Cochrane Library ${ }^{\circledR}$, PubMed ${ }^{\circledR}$ and EMBASE ${ }^{\circledR}$ with the keywords of "ultrasound", "accreta", and "predict" OR "prediction" OR "index" on each databases with certain techniques (Figure 1). Search focused on articles in diagnostic type showing diagnostic values of the studies. Reference lists of relevant articles were searched for other possibly relevant studies. After obtaining a result, a first selection was done by screening the study titles and abstracts. Eight articles were available as full text, and all of them included in our analysis.

\section{Critical appraisal}

Appraisal of 8 diagnostic studies involving 1324 patients underwent ultrasound, MRI, cell-free mRNA examination, or their combination for predicting placenta accrete was conducted finding at the diagnostic values (Se, Sp, PPV, NPV). Review study or study 
without diagnostic values reported were excluded. We used diagnostic appraisal questions developed by Centre of Evidence-Based Medicine (CEBM), University of Oxford (available at: http://www.cebm.net/ critical-appraisal/).

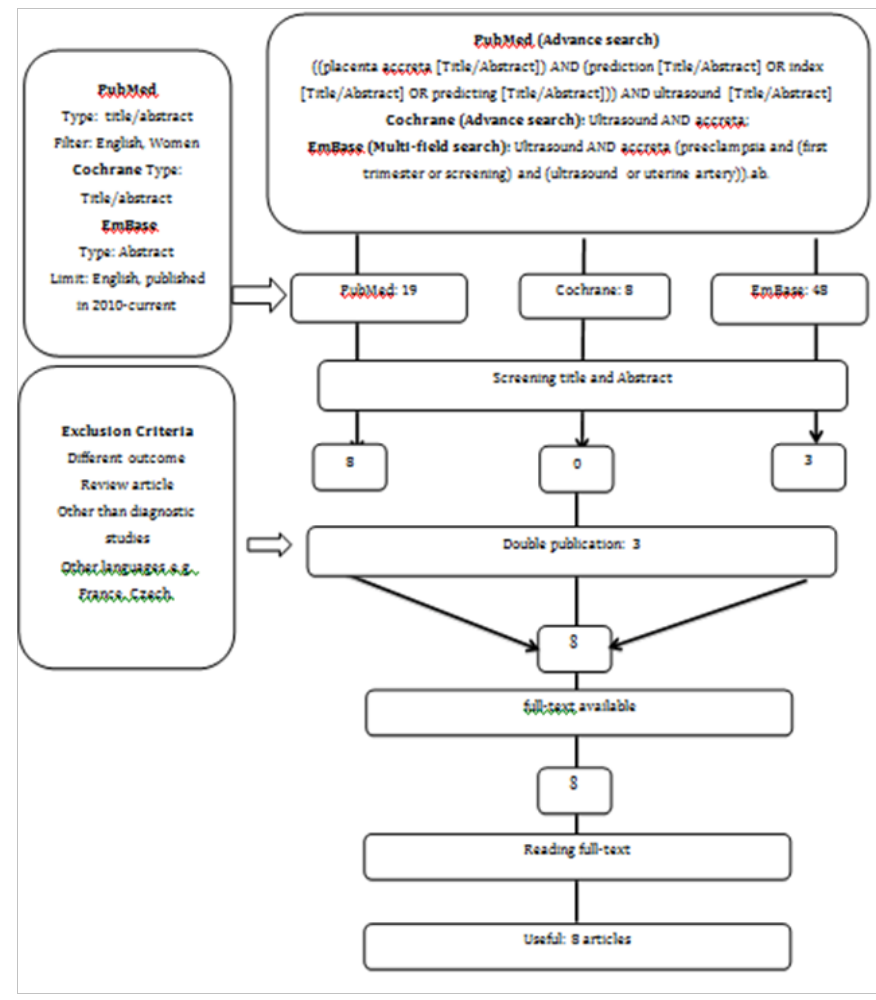

Figure I Searching Flow.

\section{Results}

Appraisal study was performed on 8 retrospective studies involving pregnant woman who had recognized risks of having placenta accreta. Doppler or 2D grey-scale color ultrasound (8 studies), MRI (3 studies), cell-free placental mRNA examination (1 study), and maternal characteristics (1 study) were respectively used in each studies either as single predictor or in combination with other variables for diagnosis of placenta accreta. The diagnosis was confirmed using histology examination in all studies. The overall rate of placenta accreta found on these studies were ranging from $8.4 \%$ to $31.8 \%$. Accuracy, Se, Sp PPV, and NPV of ultrasound in this study in detecting accreta were respectively $64.8 \%-95.3 \%, 17 \%-100 \%$, $78.9 \%-100 \%, 56 \%-100 \%$, and $64.8 \%$ - 100\%(Table $1 \& 2$ ).

The Se, Sp, PPV, and NPV of MRI in predicting placenta accreta derived from 2 studies were respectively $88.89 \%-100 \%, 100 \%$, $100 \%, 92.86 \%-100 \%$. While Se, Sp, PPV, and NPV of cell-free placental mRNA for placenta accreta prediction were respectively $91.7 \%, 78.9 \%, 57.9 \%$ and $96.8 \%$ using $3.325(\mathrm{MoM})$ as the cut-off point. On a study among 184 women with prior cesarean section, Rac et al. developed a prediction index of placenta accreta by using these parameters i.e. the smallest sagittal myometrial thickness, grade of lacunae, presence of bridging vessels, number of cesarean deliveries and placental location as significant contributors. Grade-3 lacuna (many lacuna throughout the placenta and appearing large and bizarre) had the highest OR among all significant factors (OR 10.8, $95 \%$ CI 1.4-83). This index had area under the curve of $0.87(95 \%$ confidence interval, 0.80-0.95). Placental accreta index score of more than 8 will be resulted in $96 \%$ (81-99) of probability of invasion.

Aitken et al. ${ }^{11}$ performed a retrospective review on 65 cases of women with invasive placentation diagnosed antenatally with use of ultrasound and/or MRI. MRI had higher prediction rate of abnormal invasive placentation compared to ultrasound ( $91.9 \%$ versus $98.4 \%$ ). In addition, MRI was better in predicting the stage of invasion of placenta $\left(61.3 \%\right.$ versus $38.7 \%$ of detection rate versus). ${ }^{11}$ Ibrahim et al. ${ }^{12}$ found that ultrasound and MRI had no significant difference in accuracy in diagnosing abnormal placentation (97-100\% versus 94-100\%). They concluded that MRI had higher accuracy compare to ultrasound in diagnosing myometrial invasion and the type of abnormal placentation $(73.5 \%$ versus $47 \%){ }^{12}$

Naghshineh et al. ${ }^{13}$ proposed cell-free placental mRNA as an acceptable predictor for placenta accreta. The median MoM values of cell-free placental mRNA was significantly higher among the women diagnosed with placenta accrete compared to they who had normal placentation $(6.02 \pm 1.550$ and $2.83 \pm 0.648 P<0.001)$. Respectively, $\mathrm{Se}, \mathrm{Sp}, \mathrm{PPV}$ and NPV of mRNA with using cut-off point of 3.325 were $91.7 \%, 78.9 \%, 57.9 \%$ and $96.8 \%$. These values were comparable to the accuracy of ultrasound. ${ }^{13}$

A Retrospective study conducted by Chalubinski et al. ${ }^{14}$ among 232 patients at risk for placental invasion resulted high overall accuracy of ultrasound in diagnosing placenta accreta. Se, Sp, PPV, and NPV were $91.4 \%$ (95\% CI 77.6 - 97.0), 95.9\% (95\% CI 92.2 - $97.9 \%$ ), 80.0\% (95\% CI 65.2 - 89.5\%), and 98.4\% (95\% CI 95.5 $99.5 \%$ ), respectively. ${ }^{14}$ Cho et al. ${ }^{15}$ suggests that the mean PI of uterine artery Doppler velocimetry measurement was significantly reduced in patients with placenta accreta compared to those without accreta ( 0.51 versus $0.57 ; P=.002) .{ }^{15}$ The area under the receive operating characteristic curve was 0.77 with the combination of the mean PI and previous cesarean delivery $(P=.047)$.

Kumar et al. ${ }^{16}$ found MRI were correctly diagnosed placenta accreta in 8 out of 9 subjects with histological-proven placenta accreta. While ultrasound predict correctly all of patients with placenta accreta. Dark intraplacental band had the highest diagnostic accuracy among all of MRI sign for placenta accreta (accuracy, Se, Sp, PPV, and NPV were respectively $95.45 \%, 88,89 \%, 100 \%, 100 \%$, and $92.86 \%$ ). While turubulance in the lacuna had the highest diagnostic accuracy compared to other ultrasound signs (accuracy, Se, Sp, PPV, and NPV were respectively $95.45 \%, 100 \%, 92.31 \%, 90 \%$, and $100 \%$ ). Loss of chemical shift artifacts ("India-ink line") at the bladder-myometrial interface, was an accurate sign for detection of vesical wall invasion (accuracy, Se, Sp, PPV, and NPV were respectively 95.45\%, 83.3\%, $100 \%, 100 \%$, and $94.12 \%){ }^{16}$

In 2014, Bowman et al. ${ }^{20}$ concluded that ultrasound was not as accurate as previously described. The Se, Sp, PPV, NPV, and accuracy were respectively $53.5 \%, 88.0 \%, 82.1 \%, 64.8 \%$, and $64.8 \%$. Loss of retroplacental clear space (OR, 2.4; 95\% CI, 1.1-4.9), placental lacuna (OR, 1.5; 95\% CI, 1.-1.6), and abnormalities on color Doppler (OR, $2.1 ; 95 \% \mathrm{CI}, 1.8-2.4)$ were correlated significantly with placenta accreta (OR, 2.4; 95\% CI,1.1-4.9) in their multivariate analysis. ${ }^{17}$ On our appraisal analysis, study conducted by Chalbunsiki et al. ${ }^{14}$ had the highest appraisal score (8/8). Study conducted by Ibrahim et al. ${ }^{12}$ Kumar et al. ${ }^{1}$ and Rac et al. fullfilled 7 out of 8 criteria's on our appraisal sheet. 2 studies were published without mention any value of Se, Sp, PPV, and PPV. 
Table I Characteristics and results of 8 appraised studies

\begin{tabular}{|c|c|c|c|c|c|c|c|}
\hline References & $\begin{array}{l}\text { Eligible for } \\
\text { analysis }\end{array}$ & Design & Modality & Parameters/Classification & Cutoff & Accreta Rate (\%) & Result \\
\hline Rac et al. $(20 \mid 4)$ & 184 & Retrospective review & Ultrasound & $\begin{array}{l}\text { The combination of smallest } \\
\text { sagittal myometrial thickness, } \\
\text { lacunae, and bridging vessels, in } \\
\text { addition to number of cesarean } \\
\text { deliveries and placental location. }\end{array}$ & $>8$ & $8.40 \%$ & $\begin{array}{l}\text { AUC: } 0.87 \\
\text { Invasion: } 96 \% \\
\text { Se: } 17 \% \\
\text { Spec: } 100 \% \\
\text { PPV: } 100 \% \\
\text { NPV: } 71 \%\end{array}$ \\
\hline Naghshineh ${ }^{13}$ & 50 & Cross-sectional & $\begin{array}{l}\text { Doppler } \\
\text { Ultrasound, } \\
\text { cell-free } \\
\text { placental } \\
\text { mRNA }\end{array}$ & $\begin{array}{l}\text { Turbulent or diffuse blood } \\
\text { flow through placental lacunae; } \\
\text { vessels crossing the interface } \\
\text { disruption site }\end{array}$ & $\begin{array}{l}\text { Cell Free } \\
\text { placental } \\
\text { mRNA:< } \\
3.325 \\
\text { (MoM) }\end{array}$ & $24 \%$ & $\begin{array}{l}\text { Doppler } \\
\text { ultrasound: } \\
\text { Se: } 83.3 \%, \text { Sp: } 78.9 \% \text {, } \\
\text { PPV: } 56 \% \text { and NPV } \\
94 \% \text {, } \\
\text { Cell Free } \\
\text { placental mRNA: } \\
91.7 \%, 78.9 \%, 57.9 \% \\
\text { and } 96.8 \%,\end{array}$ \\
\hline Bowman $^{17}$ & 229 & Retrospective analysis & Ultrasound & $\begin{array}{l}\text { Number of lacuna, loss of } \\
\text { retroplacental clear space, } \\
\text { loss of visualization of the } \\
\text { myometrium, and bladder wall } \\
\text { irregularity. } \\
\text { Subplacental vascularity, vessels } \\
\text { bridging from the placenta to } \\
\text { the uterine margin, gaps in } \\
\text { myometrial blood flow, vessels } \\
\text { crossing interface disruption } \\
\text { sies, or turbulent lacunae. }\end{array}$ & & $24 \%$ & $\begin{array}{l}\text { Accuracy: } 64.8 \% \\
\text { Se: } 53.5 \%, \text { Sp: } 88.0 \% \text {, } \\
\text { PPV: } 82.1 \%, \text { NPV: } \\
64.8 \%,\end{array}$ \\
\hline
\end{tabular}


Table Continued...

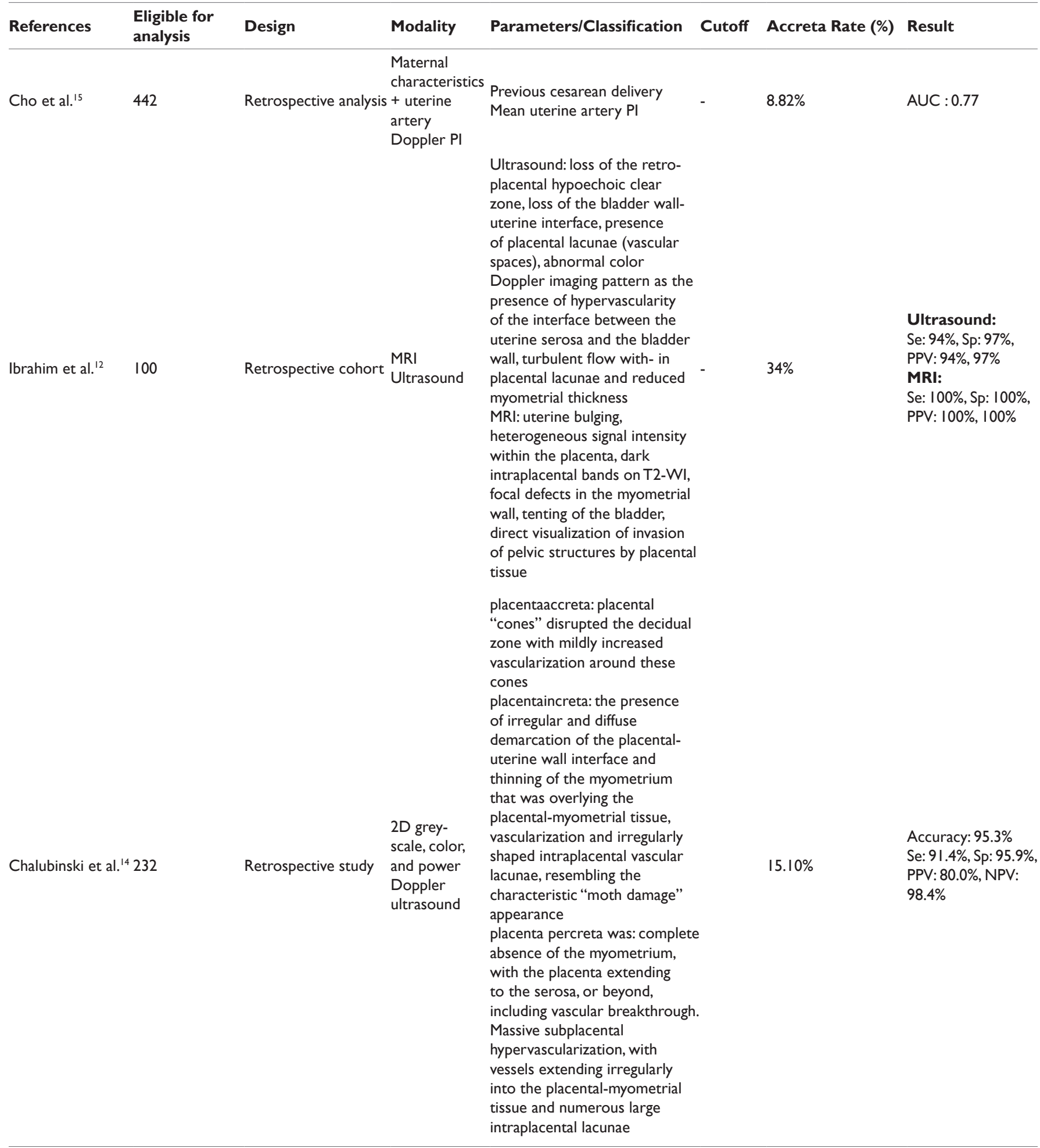

AUC: Area Under the Curve; Se: Sensitivity; Sp: Specificity; PPV: Positive Predictive Value; NPV: Negative Predictive Value; MRI: Magnetic Resonance Imaging; PI: Pulsatile Index

\section{Discussion}

The overall rate of placenta accreta found on these studies were ranging from $8.4 \%$ to 31.8 . This wide range of placenta accrete incidence could be affected by the population of study. In some studies, the study population were women at risk of placenta accrete or they who were identified as having signs of invasive placentation using ultrasound or MRI. ${ }^{11}$ While in others, data were collected from routine ultrasound screening. ${ }^{15}$ The value of ultrasound in predicting placenta accreta resulting from 8 studies were not as accurate as described in previous studies. ${ }^{18}$ Sensitivity of ultrasound for predicting placenta accrete below $70 \%$ were found in 2 studies. It was contradictory with a systematic meta-analysis that published high accuracy of ultrasound in predicting placenta accrete.${ }^{19}$ Bowman et al. ${ }^{20}$ raised contrary result 
when published a low sensitivity of ultrasound for placenta accrete. ${ }^{20}$ In addition ultrasound found to have significant interobserver variability for the diagnosis of placenta accrete. ${ }^{17}$

From the appraisal of the studies we found MRI as useful and sensitive modalities for diagnosing placenta accreta. It had comparable diagnostic accuracy compared to ultrasound. A number of studies stated that it was better in predicting the stage of invasion of placenta, ${ }^{11}$ and the type of abnormal placentation. ${ }^{12}$ It was supported by a result of meta-analysis of 18 studies involving 1010 women underwent MRI examination conducted by D'Antonio. Dark intraplacental bands on T2 weighted sequences and focal interruption of the myometrium resulted in the best sensitivity. ${ }^{19}$
Free-placental mRNA could become a promising predictor for diagnosing placenta accreta due to its unbiased measurement profile. Ultrasound is highlighted as an operator-dependent examination ultrasound in predicting placenta accrete. ${ }^{20}$ Uteroplacental transfer of cell free placental mRNA molecule resulted from thin deciduas of placenta accreta will be possibly resulted in increased plasma level of cell free placental mRNA. ${ }^{10}$ Plasma cell-free placental mRNA may increase the accuracy of ultrasound in predicting placental invasion in women at risk for placenta accrete. ${ }^{10}$ Study conducted by Chalubinski et al. ${ }^{14}$ had the highest appraisal score due to its well-defined methods and high accuracy of ultrasound revealed from their study. Kumar et al. ${ }^{16}$ and Ibrahim et al. ${ }^{12}$ did not mention the blinding and independent methods in their studies.

Table 2 Appraisal table of 8 studies

\begin{tabular}{|c|c|c|c|c|c|c|c|c|}
\hline \multirow[t]{2}{*}{ NoStudy } & \multirow[t]{2}{*}{$\begin{array}{l}\text { Eligible for } \\
\text { analysis }\end{array}$} & \multirow{2}{*}{$\begin{array}{l}\text { Validity } \\
\text { I }\end{array}$} & \multicolumn{2}{|l|}{ Result } & \multirow[b]{2}{*}{ 6(ppv) } & \multirow[b]{2}{*}{7 (npv) } & \multirow{2}{*}{$\begin{array}{l}\text { Applicability } \\
8\end{array}$} & \multirow{2}{*}{$\begin{array}{l}\text { Total } \\
\text { score }\end{array}$} \\
\hline & & & 234 (se) & 5 (sp) & & & & \\
\hline I. Rac, et al (20I4) & 184 & + & $++17 \%$ & $100 \%$ & $100 \%$ & $71 \%$ & + & $7 / 8$ \\
\hline 2. Aitken et al." & 65 & + & ++- & - & - & - & - & $3 / 8$ \\
\hline $3 \begin{array}{l}\text { Naghshineh }{ }^{13} \text { (Ultrasound) } \\
\text { Naghshineh }^{13} \text { (Cell Free placental mRNA) }\end{array}$ & 50 & + & $+? \begin{array}{l}83.3 \% \\
91.7 \%\end{array}$ & $\begin{array}{l}78.9 \% \\
78.9 \%\end{array}$ & $\begin{array}{l}56 \% \\
57.9 \%\end{array}$ & $\begin{array}{l}94 \% \\
96.8 \%\end{array}$ & $\begin{array}{l}+ \\
-\end{array}$ & $5 / 8$ \\
\hline $4 \begin{array}{l}\text { Kumar et al. }{ }^{16} \text { (Ultrasound) } \\
\text { Kumar et al. }{ }^{16} \text { (MRI) }\end{array}$ & 22 & + & $+? \begin{array}{l}100 \% \\
88.9 \%\end{array}$ & $\begin{array}{l}92.31 \\
100 \%\end{array}$ & $\begin{array}{l}90 \% \\
100 \%\end{array}$ & $\begin{array}{l}100 \% \\
92.86 \%\end{array}$ & + & $7 / 8$ \\
\hline 5 Bowman ${ }^{17}$ & 229 & + & $++53.5 \%$ & $88.0 \%$ & $82.1 \%$ & $64.8 \%$ & + & $6 / 8$ \\
\hline 6 Cho et al..$^{15}$ & 442 & + & $+?-$ & - & - & - & + & $3 / 8$ \\
\hline $\begin{array}{l}7 \text { Ibrahim et al. }{ }^{12} \text { (ultrasound) } \\
\text { Ibrahim et al. } .^{12} \text { (MRI) }\end{array}$ & 100 & + & $+? \begin{array}{l}94 \% \\
100 \%\end{array}$ & $\begin{array}{l}97 \% \\
100 \%\end{array}$ & $\begin{array}{l}94 \% \\
10 \%\end{array}$ & $\begin{array}{l}97 \% \\
100 \%\end{array}$ & + & $7 / 8$ \\
\hline 8 Chalubinski et al. ${ }^{14}$ & 232 & + & $++91.4 \%$ & $95.9 \%$ & $80 / 0 \%$ & $98.4 \%$ & + & $8 / 8$ \\
\hline
\end{tabular}

I: representative patients; 2: reference standard; 3: blind \& independent; 4: sensitivity; 5: specificity; 6: positive predictive value; 7: negative predictive value; 8: detail methods to permit replication; US: ultrasound; +: adequate; -: inadequate; ?: unknown, no information given'. Every item was scored based on diagnostic study appraisal questions developed by CEBM (available at: http://www.cebm.net/critical-appraisal/)

\section{Conclusion}

Ultrasound has a wide range of diagnostic accuracy in predicting ultrasound, it could be explained by its significant interobserver variability. MRI had better diagnostic accuracy for predicting the stage of invasion of placenta. Free-placental mRNA is an objective and promising predictor for diagnosing placenta accreta. Combination of these examination could increased the accuracy of the diagnostics.

\section{Acknowledgments}

None.

\section{Conflicts of interest}

None.

\section{References}

1. Solheim KN, Esakoff TF, Little SE, et al. The effect of cesarean delivery rates on the future incidence of placenta previa, placenta accreta, and maternal mortality. J Matern Fetal Neonatal Med. 2011;24(11):13411346 .

2. Spiliopoulos M, Kareti A, Jain NJ, et al. Risk of peripartum hysterectomy by mode of delivery and prior obstetric history: data from a populationbased study. Arch Gynecol Obstet. 2010;283(6):1261-1268.

3. Belfort MA. Placenta accreta. Am J Obstet Gynecol. 2010;203(5):430 439.

4. Satija B, Kumar S, Wadhwa L, et al. Utility of ultrasound and magnetic resonance imaging in prenatal diagnosis of placenta accreta: A prospective study. Indian J Radiol Imaging. 2015;25(4):464-470.

5. O’Brien JM. Placenta Previa, Placenta Accreta, and Vasa Previa. Obstet Gynecol. 2007;109(1):203-204.

6. Esakoff TF, Sparks TN, Kaimal AJ, et al. Diagnosis and morbidity of placenta accreta. Ultrasound Obstet Gynecol. 2011;37(3):324-327.

7. Tikkanen M, Paavonen J, Loukovaara M, et al. Antenatal diagnosis of placenta accreta leads to reduced blood loss. Acta Obstet Gynecol Scand. 2011;90(10):1140-1146.

8. Angstmann T, Gard G, Harrington T, et al. Surgical management of placenta accreta: a cohort series and suggested approach. Am J Obstet Gynecol. 2010;202(1):38.e1-38.e9.

9. Dannheim K, Shainker SA, Hecht JL. Hysterectomy for placenta accreta; methods for gross and microscopic pathology examination. Arch Gynecol Obstet. 2016;293(5):951-958.

10. Behery El MM, Rasha L E, Alfy El Y. Cell-free placental mRNA in maternal plasma to predict placental invasion in patients with placenta accreta. Int J Gynecol Obstet. 2010;109(1):30-33.

11. Aitken K, Allen L, Pantazi S, et al. MRI Significantly Improves Disease Staging to Direct Surgical Planning for Abnormal Invasive Placentation: A Single Centre Experience. J Obstet Gynaecol Can. 2016;38(3):246. e1-251.e1.

12. Algebally AM, Yousef RR, Badr SS, et al. The Value of Ultrasound and Magnetic Resonance Imaging in Diagnostics and Prediction of Morbidity in Cases of Placenta Previa with Abnormal Placentation. Pol J Radiol. 2014;79:409-416. 
13. Khorvash E, Kamali S, Naghshineh E. A comparison of cell-free placental messenger ribonucleic acid and color Doppler ultrasound for the prediction of placental invasion in patients with placenta accreta. Adv Biomed Res. 2015;4(1):31.

14. Chalubinski KM, Pils S, Klein K, et al. Prenatal sonography can predict degree of placental invasion. Ultrasound Obstet Gynecol. 2013;42(5):518-524.

15. Cho HY, Hwang HS, Jung I, et al. Diagnosis of Placenta Accreta by Uterine Artery Doppler Velocimetry in Patients With Placenta Previa. $J$ Ultrasound Med. 2015;34(9):1571-1575.

16. Kumar I, Verma A, Ojha R, et al. Invasive placental disorders: a prospective US and MRI comparative analysis. Acta Radiol. 2016;pii:0284185116638567.
17. Bowman ZS, Eller AG, Kennedy AM, et al. Accuracy of ultrasound for the prediction of placenta accreta. Am JObstet Gynecol.2014;211(2):177. e1-177.e7.

18. Woodring TC, Klauser CK, Bofill JA, et al. Prediction of placenta accreta by ultrasonography and color doppler imaging. J Matern Fetal Neonatal Med. 2010;24(1):118-121.

19. D'Antonio F, Iacovella C, Palacios-Jaraquemada J, et al. Prenatal identification of invasive placentation using magnetic resonance imaging: systematic review and meta-analysis. Ultrasound Obstet Gynecol. 2014;44(1):8-16.

20. Bowman ZS, Eller AG, Kennedy AM, et al. Interobserver Variability of Sonography for Prediction of Placenta Accreta. J Ultrasound Med. 2014;33(12):2153-2158 